\title{
Recombinant HMG1 Protein Produced in Pichia pastoris: A Nonviral Gene Delivery Agent
}

BioTechniques 22:718-729 (April 1997)

\begin{abstract}
A.R. Mistry, L. Falciola 1 , L. Monaco ${ }^{1}$, R. Tagliabue ${ }^{1}$, G. Acerbis ${ }^{1}$, A. Knight, R.P. Harbottle, M. Soria ${ }^{1}$, M.E. Bianchi ${ }^{1,2}$, C. Coutelle and S.L. Hart Imperial College School of Medicine at St. Mary's, London, England, UK; ${ }^{1}$ San Raffaele Scientific Institute, Milan; ${ }^{2}$ Dipartimento di Genetica di Biologia dei Microrganismi, Milan, Italy
\end{abstract}

\footnotetext{
ABSTRACT

This paper describes the production of a recombinant protein from the expression system based on the methylotrophic yeast Pichia pastoris. Efficient production of rat high-mobility-group 1 (HMG1) protein was obtained using the system. Two forms of $H M G 1$ were secreted into the culture medium: a 24.5-kDa species corresponding to the native HMG1 and a 32-kDa glycosylated derivative. Non-glycosylated recombinant HMG1 was purified easily and shown to possess the same DNA-binding properties as HMG1 purified from calf thymus. Plasmid DNA complexed to the recombinant HMG1 is taken up by a variety of mammalian cells in culture. Transient expression of a luciferase reporter gene was observed. Under selective conditions, stable expression of a neomycin gene was established as a result of integration into the genome. HMG1-mediated gene delivery was as efficient as calcium phosphate-mediated transfection but without associated cell damage. In addition, stable transfectants obtained after selection for 6418 resistance usually integrated only one copy of the transfected DNA in contrast to the high unpredictable number obtained by the calcium phosphate method. HMGl transfection complexes were not toxic to cultured cells, even at high concentrations.
}

\section{INTRODUCTION}

High-mobility-group 1 (HMG1) protein is an abundant, nonhistone, chromosomal protein that is highly conserved in all vertebrates (7). It has a molecular weight of $24.5 \mathrm{kDa}$ and is capable of binding cruciform DNA $(3,5)$, negatively supercoiled plasmid DNA (25) and single-stranded DNA (16). Although the precise functional roles of HMG1 have yet to be fully defined, it has been implicated in replication and transcription (7). The protein contains two homologous HMG boxes rich in basic amino acids and an acidic tail at the carboxyl terminus. HMG boxes are highly conserved domains of about 80 amino acids found in several DNA-binding proteins, many of which are transcription factors (15).

We are investigating the use of HMG1 as a nonviral gene delivery agent. The use of HMG1 in gene-transfer complexes has been described in two different modes. First, HMG1packaged plasmid DNA forms condensed complexes capable of transfecting cells with high efficiency (6). Second, HMG1 has been incorporated into complexes with liposomes, Sendai virus, erythrocyte membranes and plasmid DNA (17). These hybrid vesicles fuse with and enter cells while the association of HMG1 with DNA is thought to facilitate its packaging and transport to the nucleus of nondividing cells. These reports suggest that HMG1 protein could find further applications in the generation of nonviral gene-delivery systems.

The first requirement for the exploitation of HMG1 in gene-transfer complexes was a ready source of the protein. It is possible to extract HMG1 from tissues such as calf thymus (19). However, this is a time-consuming and complex process requiring large amounts of starting tissue. Furthermore, HMG1 yields from this source are heterogeneous in composition and DNA-binding properties (28). Recombinant $E$. coli containing HMG1 cDNA have generated only low yields of HMG1 $(20 \mu \mathrm{g} / \mathrm{L})$, since this protein is toxic to the bacteria and is rapidly degraded intracellularly (4).

This paper reports the high-level production, purification and characterization of secreted HMG1 recombinant protein from Pichia pastoris and demonstrates the ability to use the recombinant protein as a reliable, inexpensive method to introduce DNA into cells. The methylotrophic yeast $P$. pastoris has been reported previously to produce high levels of heterologous proteins (10) including human serum albumin (2), invertase (26), mouse epidermal growth factor (9) and aprotinin (27). One of the advantages of this eukaryotic expression system is the ability to secrete high levels of recombinant protein into a protein-free growth medium, facilitating protein purification.

\section{MATERIALS AND METHODS}

\section{Construction of an HMG1 Expres- sion Plasmid-pPIC9-HMG1}

A $P$. pastoris HMG1-producing expression vector, pPIC9-HMG1 (Figure 1A), was constructed by subcloning rat HMG1 cDNA into the expression vector pPIC9 (Invitrogen $B V, \mathrm{NV}$ Leek, Holland), which contains an alpha F secretion signal derived from Saccharomyces cerevisiae and a HIS gene for selection of Pichia transformants. A DNA fragment encoding rat HMG1 was amplified from the bacterial expression plasmid pT7-RNHMG1 (4) by the polymerase chain reaction (PCR) using Pfu DNA Polymerase (Stratagene, Cambridge, England, UK). 


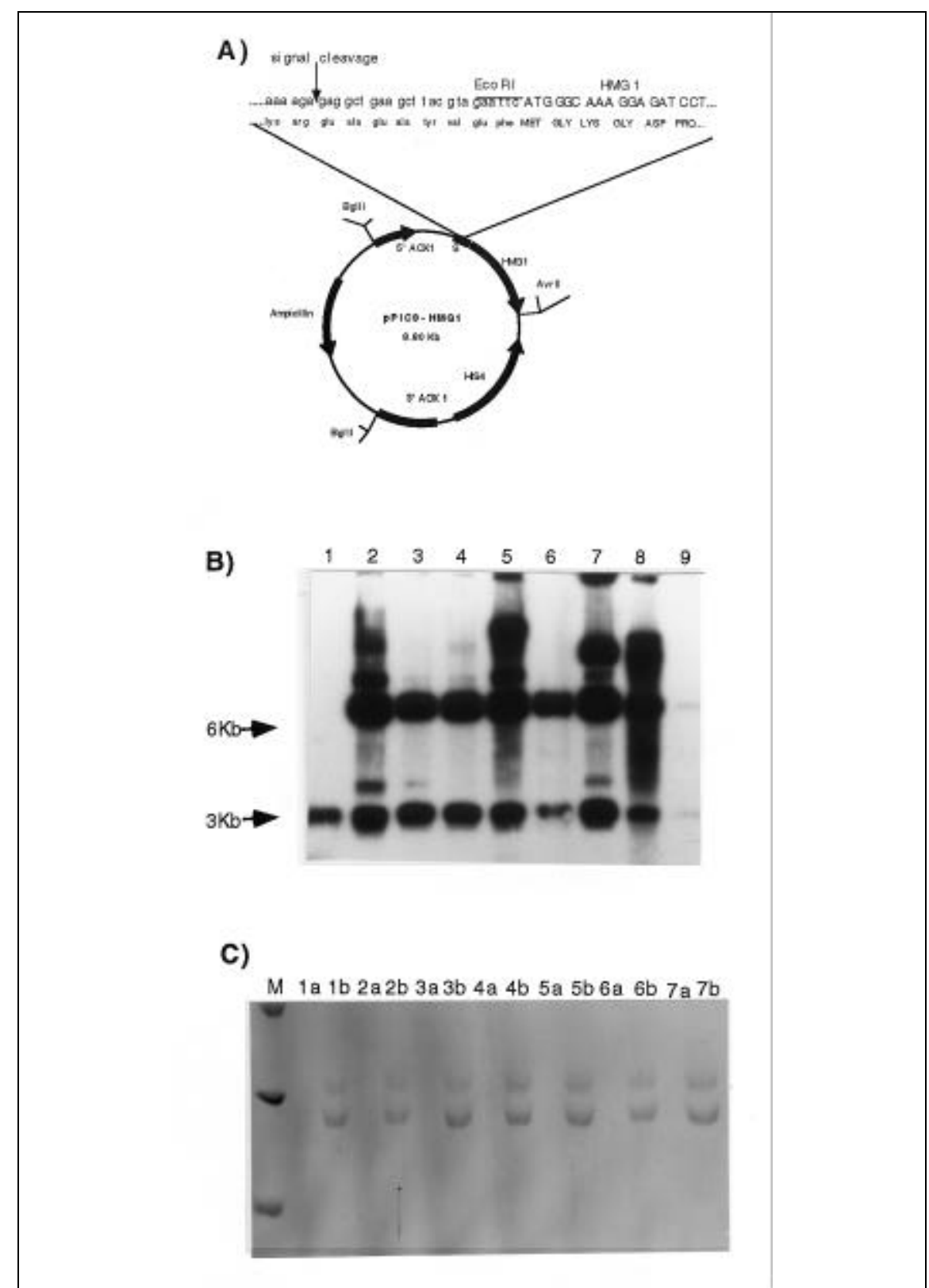

Figure 1. Construction of the vector for expression of HMG1 and generation of $P$. pastoris strains that secrete HMG1 in medium. (A) The plasmid pPIC9-HMG1 was constructed by amplifying cDNAencoding HMG1 by PCR using primers that contain EcoRI and AvrII sites. This fragment was subcloned into the pPIC9 vector to produce a fusion in frame with the $\alpha$-factor secretion signal (S). The plasmid map shows the $A O X 1$ promoter and terminator upstream and downstream, respectively, of the HMG1 cDNA. (B) Southern blot analysis of genomic DNA from various Pichia $\mathrm{His}^{+} / \mathrm{Mut}^{\mathrm{s}}$ clones. The DNA of transformed Pichia $\mathrm{His}^{+} / \mathrm{Mut}^{\mathrm{s}}$ clones was digested with BglII and the filter hybridized with a HIS4 probe. lane M, 1-kb marker; lane 1, untransformed P. pastoris strain GS115; lane 2, DD8; lane 3, DD2; lane 4, F10; lane 5, F11; lane 6, CC5; lane 7, D3; lane 8, G10; lane 9, A12. Two main bands are seen: a 2.7-kb band, present in all lanes representing the mutant chromosomal his4 gene and a 6.4-kb band representing the $B g l I I$ fragment of the expression cassette. The bands are weak in lane 9 because of relatively low yield of genomic DNA in the plug. Clones CC5, DD8 and DD2 are derived from a colony hybridization blot not shown. (C) P. pastoris clones containing multiple integrations of HMG1 expression cassette were grown in glycerol-containing media (BMGY) and were then resuspended in methanol-containing media (BMMY) to induce expression from the $A O X 1$ promoter. (a) $10 \mu \mathrm{L}$ of BMGY media (uninduced) were analyzed alongside (b) $10 \mu \mathrm{L}$ of BMMY media (induced) from each of the selected clones. The gel was stained with Coomassie blue. Lane M, low-molecular-weight protein markers (Bio-Rad); lanes 1a and $1 \mathrm{~b}$, clone DD8; lanes 2a and 2b, clone DD2; lanes 3a and 3b, clone F10; lanes 4a and 4b, clone F11; lanes $5 \mathrm{a}$ and $5 \mathrm{~b}$, clone CC5; lanes $6 \mathrm{a}$ and $6 \mathrm{~b}, \mathrm{D} 3$; lanes $7 \mathrm{a}$ and $7 \mathrm{~b}, \mathrm{G} 10$. Two species of protein $(24.5$ and $32 \mathrm{kDa}$ ) can be seen in each of the lanes derived from clones induced with BMMY.
Transformation of $P$. pastoris and Selection of Integrants

Plasmid pPIC9-HMG1 was digested with BglII (Life Technologies, Paisley, Scotland, UK) to produce a linear DNA molecule with ends homologous to the $5^{\prime}$ and $3^{\prime}$ termini of the alcohol oxidase gene $(A O X I)$, whose product is involved in the first step of methanol metabolism. Integration into the host yeast cell AOX1 locus occurs by double crossover recombination resulting in the complete removal of the AOXI coding region and, consequently, the loss of the ability to utilize methanol efficiently (8). The linearized DNA was used to transform the P. pastoris strain GS115 (his4) to the His ${ }^{+}$phenotype by the spheroplast method (8). Muts transformants were identified by picking individual $\mathrm{His}^{+}$transformants and patching onto a minimal methanol media plate, then onto minimal glucose media plates as described in the maufacturer's instructions (Invitrogen $B V$ ).

\section{DNA Analysis}

Successful expression of recombinant proteins in $P$. pastoris often depends upon the generation of recombinant strains that contain multiple copies of the gene integrated at the $A O X I$ locus (8). A DNA dot-blot analysis was performed to select multicopy transformants (23).

The number of copies of HMG1 integrated into the Pichia genome was determined essentially as described by Clare et al. (8). Yeast DNA was prepared in low-melting-point agarose plugs using an adaptation of the spheroplast/lithium-dodecyl-sulphate procedure (1). A one-third segment of each plug was incubated in a final volume of $500 \mu \mathrm{L}$ with $100 \mathrm{U}$ of $B g l \mathrm{II}$, electrophoresed on an agarose gel $(0.8 \%)$ and then blotted onto a nylon membrane. A gel-purified, 0.6-kb KpnI HIS4 fragment was labeled with ${ }^{32} \mathrm{P}[\mathrm{ATP}]$ using the random priming method (12) and used as a probe for Southern analysis. Following hybridization, the filter was dried and exposed to an X-ray film, and then the relative amounts of the probe bound to the bands were determined by a PhosphorImager ${ }^{\mathrm{TM}}$ (Molecular Dynamics, Sunnyvale, CA, USA). 


\section{Protein Expression and Analysis}

A small number of cells from the appropriate clones were inoculated in 50 $\mathrm{mL}$ of buffered complex glycerol medium (BMGY; per L: $10 \mathrm{~g}$ of yeast extract, $20 \mathrm{~g}$ of peptone, $13.4 \mathrm{~g}$ of yeast nitrogen base, $400 \mu \mathrm{g}$ of biotin, $10 \mathrm{~mL}$ of glycerol and $100 \mathrm{~mL}$ of $1 \mathrm{M}$ potassium phosphate buffer, pH 6.0, in a 250$\mathrm{mL}$ baffled flask. The cells were incubated at $30^{\circ} \mathrm{C}$ with vigorous shaking (300 rpm) for 2 days until the $A_{600}$ was between 5 and 10. After harvesting by centrifugation, the cells were resuspended in $20 \mathrm{~mL}$ of buffered complex methanol media (BMMY; same composition as BMGY medium except that $5 \mathrm{~mL}$ of methanol per L were substituted for glycerol). Yeast cultures were then returned to the shaker for one additional day. At the end of this period, the yeast cells were harvested, and 10 $\mu \mathrm{L}$ of the supernatant were analyzed on a $10 \%$ sodium dodecyl sulfate (SDS) polyacrylamide gel stained with Coomassie $^{\circledR}$ blue or by immunoblotting with chicken polyclonal anti-rat HMG1. The protein concentration was determined by the Bradford assay (BioRad, Herts, England, UK) using bovine serum albumin (BSA) as the standard or spectroscopically using the extinction coefficient value of $33000 \mathrm{M} / \mathrm{cm}$ (18).

Proteins were transferred from SDSpolyacrylamide gel electrophoresis (PAGE) gels to Immobilon ${ }^{\circledR}$ filters (Millipore, Bedford, MA, USA) using a Semi-Dry Blot Apparatus (Biometra, Goettingen, Germany). The filter was blocked overnight in TBSN $(50 \mathrm{mM}$ Tris-HCl, pH 8.0, $150 \mathrm{mM} \mathrm{NaCl}, 0.1 \%$ Nonidet $^{\circledR}$ P-40 [NP40]) and 1\% BSA. HMG1 was detected using a chicken polyclonal affinity-purified antibody raised against a deletion mutant of rat HMG1 containing the two HMG boxes (residues 1-176) (11). The secondary antibody was an alkaline phosphataseconjugated goat anti-chicken IgG antibody (Sigma Chemical, Poole, England, UK).

\section{Large-Scale Purification of HMG1}

Pichia-produced HMG1 was purified from $250 \mathrm{~mL}$ BMMY medium after growth of $P$. pastoris at $30^{\circ} \mathrm{C}$ with vigorous shaking (300 rpm) for $16 \mathrm{~h}$. The culture supernatant was clarified by centrifugation and acidified with concentrated acetic acid to $\mathrm{pH}$ 4.0. After filtration through a $0.45-\mu \mathrm{m}$ poresized filter, the medium was applied (at $2 \mathrm{~mL} / \mathrm{min}$ ) in $30-\mathrm{mL}$ batches to a $1-\mathrm{mL}$ HiTrap ${ }^{\circledR}$ SP Pre-Packed Column (Pharmacia Biotech, St. Albans, UK) equilibrated in $50 \mathrm{mM}$ sodium acetate $(\mathrm{pH}$ 4.0). After each loading step, total protein was eluted with $5 \mathrm{~mL}$ of $1 \mathrm{M} \mathrm{NaCl}$ in $50 \mathrm{mM}$ sodium acetate $(\mathrm{pH} 4.0)$. The elution buffer was then changed to Concanavalin A (Con A) buffer (20 $\mathrm{mM}$ Tris- $\mathrm{HCl}, \mathrm{pH} 7.5,0.5 \mathrm{M} \mathrm{NaCl}, 1$ $\mathrm{mM} \mathrm{CaCl} 2,1 \mathrm{mM} \mathrm{MnCl} 2$ and $1 \mathrm{mM}$ dithiothreitol [DTT]) using PD-10 Columns (Pharmacia Biotech). The protein was applied $(2 \mathrm{~mL} / \mathrm{min})$ to a C10/10 Chromatography Column filled with $5 \mathrm{~mL}$ Con A CL-4B Sepharose ${ }^{\circledR}$ (both from Pharmacia Biotech) equilibrated in Con A buffer. The flowthrough was concentrated, and the buffer was changed to $\mathrm{Q}$ buffer $(50 \mathrm{mM}$ HEPES, pH 7.9, $20 \mathrm{mM} \mathrm{NaCl}, 1 \mathrm{mM}$ DTT and $0.2 \mathrm{mM}$ phenazine methosulfate [PMSF]). The glycosylated form of the HMG1 can be recovered from the Con $\mathrm{A}$ using $0.1 \mathrm{M}$ sodium acetate $(\mathrm{pH}$ 3.5). Non-glycosylated recombinant HMG1 was finally purified on a $1-\mathrm{mL}$ HiTrap Q Column (Pharmacia Biotech) equilibrated in $\mathrm{Q}$ buffer and then eluted using a gradient from $20 \mathrm{mM}$ to $1 \mathrm{M}$ $\mathrm{NaCl}$ in $\mathrm{Q}$ buffer, collecting the fractions between 0.4 and $0.6 \mathrm{M} \mathrm{NaCl}$. The protein was stored in $\mathrm{F}$ buffer $(100 \mathrm{mM}$ HEPES, pH 7.9, $100 \mathrm{mM} \mathrm{NaCl}, 0.5$ mM EDTA, 5\% glycerol, $1 \mathrm{mM}$ DTT and $0.2 \mathrm{mM}$ PMSF) at $-20^{\circ} \mathrm{C}$. There is no loss of activity of HMG1 upon repeated freezing and thawing. HMG1 was purified from calf thymus using the protocol described previously (19), with an additional purification step on the HiTrap Q column to remove traces of degraded protein as described previously.

\section{DNA Binding Assays}

Gel retardation of HMG1-plasmid DNA complexes was carried out essentially as described by Sheflin et al. (24) but with a few minor alterations. The electrophoretic mobility of HMG1plasmid DNA complexes was assessed by analyzing complexes containing 0.6 $\mu \mathrm{g}$ of plasmid pGL2 (Promega, Southampton, England, UK) with a range of HMG1 concentrations $(0.02-0.8 \mu \mathrm{g} /$ $\mu \mathrm{L})$ in complex buffer $(10 \times=0.1 \mathrm{M}$ Tris- $\mathrm{HCl}, \mathrm{pH} 8.0$ and $1.5 \mathrm{M} \mathrm{NaCl}$ ) in a reaction volume of $45 \mu \mathrm{L}$. The mixture was incubated at room temperature (RT) for $30 \mathrm{~min}$. Loading dye containing $0.25 \%$ Bromophenol Blue, $20 \%$ Ficoll $^{\circledR}$ and 0.1 M EDTA was then added ( $1 / 10 \mathrm{vol})$, and the samples were loaded onto a $1 \%$ agarose gel and electrophoresed for $2-4 \mathrm{~h}$ at $6 \mathrm{~V} / \mathrm{cm}$ in $1 \times$ TBE buffer (0.09 M Tris-borate, $2 \mathrm{mM}$ EDTA), stained with $0.5 \mu \mathrm{g} / \mathrm{mL}$ of ethidium bromide (EtdBr) for $45 \mathrm{~min}$ and then photographed.

Duplex and four-way junction DNA molecules were obtained by annealing the appropriate oligonucleotides, one of which was labeled with ${ }^{32} \mathrm{P}$ using $\mathrm{T} 4$ polynucleotide kinase, and were purified by gel electrophoresis (3). Junction $\mathrm{z}$ is composed of four strands of $30 \mathrm{nu}-$ cleotides each. As controls for structure-specific binding, we used linear duplex DNAs az and bz, with the same sequences of the junction (13). DNA binding buffer ( $12 \mu \mathrm{L}$ of final volume) contained $8 \%$ Ficoll, $200 \mathrm{mM} \mathrm{NaCl}, 10$ mM HEPES, $\mathrm{pH}$ 7.9, 0.05\% NP40, 0.5 mM DTT. To these components, synthetic four-way junction DNAs or linear duplex DNAs and purified polypeptides (final concentrations are indicated in the figure legends) were added in various combinations. After incubation for $5 \mathrm{~min}$ on ice, $10-\mu \mathrm{L}$ samples were applied to vertical $6.5 \%$ polyacrylamide gels in $0.5 \times$ TBE and electrophoresed at $11 \mathrm{~V} / \mathrm{cm}$ at RT. The gel was then dried and autoradiographed.

\section{Transfection of Cells with Recombi- nant HMG1-DNA Complexes}

The plasmid pGL2 control that encodes American Firefly Luciferase under the control of a simian virus 40 (SV40) promoter and enhancer was used as a reporter gene. Yeast medium containing HMG1 was changed to 50 $\mathrm{mM}$ Tris-HCl, pH 7.5, $200 \mathrm{mM} \mathrm{NaCl}$ using 10 DG columns (Bio-Rad) and concentrated up using a Centricon ${ }^{\circledR}-10$ concentrator (Amicon, Gloucestershire, England, UK). DNA-HMG1 complexes were prepared by mixing $5 \mu \mathrm{g}$ of 


\section{Research Reports}

DNA with $300 \mu \mathrm{g}$ of the nonpurified recombinant HMG1. Serum-free OPTIMEM $^{\circledR}$ Medium (Life Technologies) was then added to give a final volume of $200 \mu \mathrm{L}$. Five micrograms of naked pGL2 plasmid DNA were mixed with OPTIMEM and used as a control to indicate any transfection mediated by the presence of HMG1. Caco-2 cells were plated in six-well plates (Falcon ${ }^{\circledR}$; Corning Costar, Cambridge, MA, USA) at a density of $2 \times 10^{5}$ cells per well and incubated for $12 \mathrm{~h}$ to approximately $50 \%$ confluent. The medium was removed, the cells were washed with phosphate-buffered saline (PBS) and resuspended in $800 \mu \mathrm{L}$ of OPTIMEM medium before addition of DNA-HMG1 complexes or plasmid DNA alone. After $4 \mathrm{~h}$, wells were washed with PBS to remove complexes, and 2 mL Dulbecco's modified Eagle medium (DMEM) containing 20\% fetal calf serum (FCS) were added.
Forty-eight hours after the application of transfection complexes, the cells were again washed with PBS, and then $200 \mu \mathrm{L}$ of Reporter Lysis Buffer (Promega) were added. The cells were scraped from the plates, and a $20-\mu \mathrm{L}$ aliquot of the lysate was mixed with $100 \mu \mathrm{L}$ of Luciferase Assay Reagent (Promega). The levels of luciferase activity were measured on a Model LB9501N Luminometer (EG\&G Berthold, Oak Ridge, TN, USA).

Plasmid pSfiSVneo (22) was used to transfect cells for selection of stable transfectants. DNA/HMG1 complexes were prepared by mixing plasmid DNA at $0.4 \mu \mathrm{g} / \mu \mathrm{L}$ in $\mathrm{H}_{2} \mathrm{O}$ with 2 vol of the homogeneous non-glycosylated HMG1 at $4 \mu \mathrm{g} / \mu \mathrm{L}$ in $50 \mathrm{mM}$ Tris- $\mathrm{HCl}, \mathrm{pH} 7.5$, $200 \mathrm{mM} \mathrm{NaCl}$. The mixture was allowed to stand at RT for $15 \mathrm{~min}$ before transfection. Complex formation was checked by DNA mobility retardation on $0.8 \%$ agarose gels. $\mathrm{CHO} \mathrm{dhfr}^{-}$cells were maintained in alpha minimum essential medium (MEM) with nucleosides and nucleotides (Sigma Chemical), supplemented with $10 \%$ FCS (Biological Industries, Kibbutz Beit Haemek, Israel), $500 \mathrm{mg} / \mathrm{mL}$ gentamycin and $40 \mathrm{U} / \mathrm{mL}$ of nystatin (both from Life Technologies). The day before transfection, cells were plated at 5 $\times 10^{5}$ cells/dish in 35-mm dishes. HMG1-mediated transfection was performed by adding $6 \mu \mathrm{L}$ of DNA/HMG1 complex (corresponding to $800 \mathrm{ng}$ of DNA and $1.6 \mu \mathrm{g}$ of protein) to each well containing $2 \mathrm{~mL}$ of growth medium supplemented with $10 \%$ FCS and $10 \mathrm{mM} \mathrm{CaCl}_{2}$. Sixteen hours later, the growth medium was changed, and 2 days after transfection, cells were passed into 60-mm dishes where selective medium containing $900 \mu \mathrm{g} / \mathrm{mL}$ of G418 (Life Technologies) was added. Resistant colonies appeared after 15-20 days. For comparison, cells were 
transfected in parallel with the same amount of DNA per plate (800 ng) and $2 \mu \mathrm{g}$ Lipofectin ${ }^{\circledR}$ (Life Technologies) following the manufacturer's instructions or by calcium phosphate co-precipitation (14). Colonies were fixed and stained with crystal violet before scoring; alternatively, colonies were individually transferred to 96-well plates and expanded for Southern blot analysis.

Genomic DNA was extracted from each G418-resistant clone according to Miller et al. (21) and cleaved with HindIII and NcoI or alternatively, with either BamHI or XbaI (enzymes all from Promega). As quantitative standards, exactly $3 \mu \mathrm{g}$ of each HindIII/ NcoI-digested sample were loaded onto a $1 \%$ agarose gel along with known amounts of plasmid pSfiSVneo digested with the same enzymes. In parallel, 0.5-3 $\mu \mathrm{g}$ from each BamHI- and XbaIdigested sample were loaded onto $0.8 \%$ gels. After electrophoresis, DNA was blotted onto nylon Biodyne ${ }^{\circledR} \mathrm{B}$ membranes (Pall BioSupport, Port Washington, NY, USA). The 916-bp fragment from the HindIII/NcoI-digested pSfiSVneo plasmid was radioactively labeled according to the multi-prime technique. Hybridization was performed as described by Meinkoth and Wahl (20); autoradiography was carried out at $-80^{\circ} \mathrm{C}$ with an intensifying screen. The band intensity from the HindIII/NcoI-digested DNA was measured using a Computing Densitometer ${ }^{\mathrm{TM}}$ (Molecular Dynamics), and the copy number per genome of integrated plasmids was calculated by comparison to the band intensity of the quantitative standards.

\section{RESULTS}

Construction of pPIC9-HMG1 and Identification of Pichia Clones with a High Copy Number of Integrated pPIC9-HMG1 DNA

The plasmid pPIC9-HMG1 (Figure 1A) was made by PCR-subcloning the rat HMG1 cDNA into the $P$. pastoris expression vector pPIC9 in frame with the alpha $\mathrm{F}$ protein secretion signal of $S$. cerevisiae. $P$. pastoris strain GS115 (his4) was transformed with the BglII fragment of plasmid pPIC9-HMG1. Transformed clones were selected for their ability to grow in the absence of histidine and further screened for integration into the $A O X 1$ locus by their inability to utilize methanol efficiently $\left(\mathrm{Mut}^{\mathrm{s}}\right)$. The initial transformation efficiency to $\mathrm{Mut}^{\mathrm{s}}$ was approximately $24 \%$. DNA dot-blot analysis of these clones probed with HMG1 cDNA (results not shown) indicated that approximately $5 \%$ of the $\mathrm{Mut}^{\mathrm{s}}$ transformants

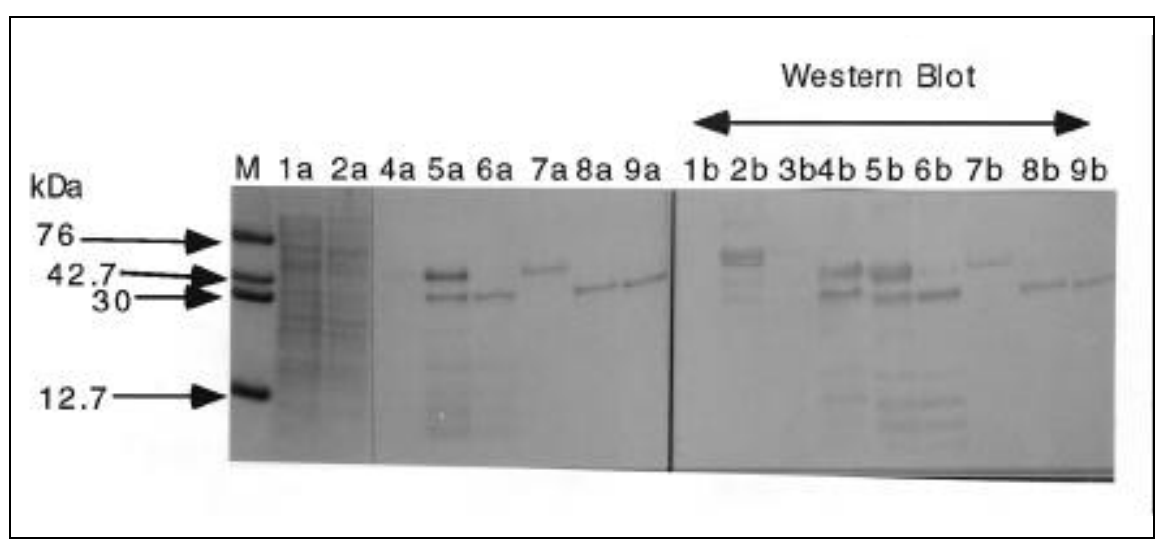

Figure 2. Purification of recombinant HMG1. Lanes a: Coomassie-stained SDS-PAGE; lanes b: Western blot of a parallel gel stained with chicken affinity-purified anti-HMG1 antibodies and an alkaline phosphatase-conjugated goat anti-chicken secondary antibody. Lane 1, extract of methanol-induced $P$. pastoris cells transformed with pPIC9; lane 2, extract of methanol-induced $P$. pastoris cells transformed with pPIC9-HMG1; lane 3, media of induced $P$. pastoris cells transformed with pPIC9; lane 4, media of induced $P$. pastoris transformed with pPIC9-HMG1; lane 5, fraction eluted from HiTrap SP Column; lane 6, flow-through of the Con A column; lane 7, fraction eluted from the Con A column; lane 8, fraction eluted from the HiTrap Q Column; lane 9, HMG1 purified from calf thymus. The irregular run of lane 4 is due to the acidity of medium in the sample. Western blot analysis of media obtained from pPIC9 is not shown. 


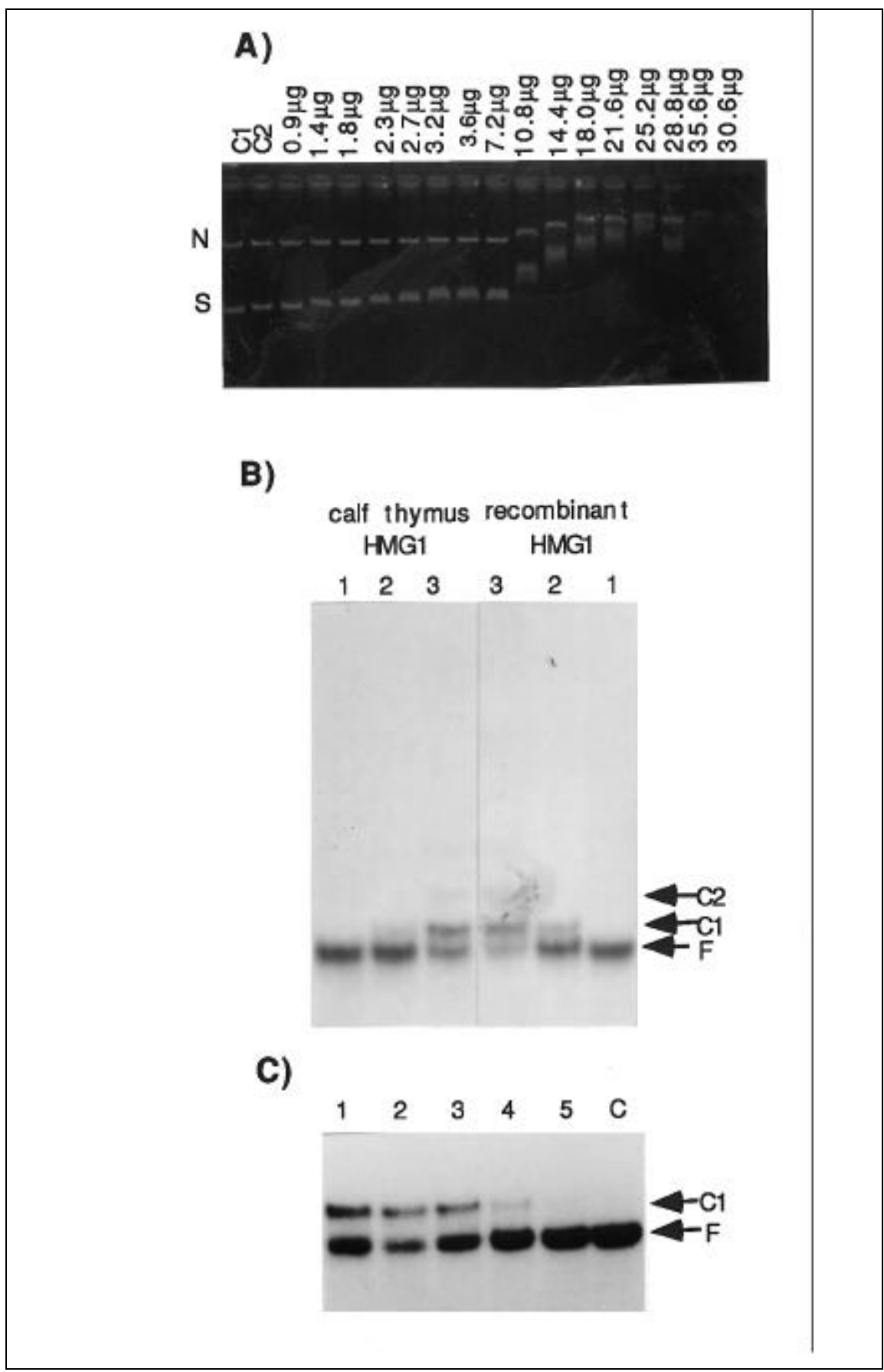

Figure 3. DNA binding properties of recombinant HMG1. (A) Binding to supercoiled plasmid DNA. Plasmid pGL2 ( $0.6 \mu \mathrm{g}$ per lane) was incubated with increasing amounts of recombinant HMG1. Control lane $\mathrm{C} 1$ contained only the pGL2 plasmid, while control lane C2 contained $790 \mu \mathrm{g}$ of BSA (indicating that the subsequent retardation is not just due to the presence of a protein). The DNA used contained negatively supercoiled DNA (S) and nicked circular (N). (B) Binding to four-way junction DNA. Various amounts of HMG1 (lane 1, $10 \mathrm{ng}$; lane 2, $50 \mathrm{ng}$; lane 3, $250 \mathrm{ng}$ ) were added to binding buffer containing $1.5 \mathrm{nM}$ labeled cruciform DNA $\mathrm{z}$. The faster-migrating band $(\mathrm{F})$ is the free-junction DNA, the slower is the protein-junction DNA complex (C1). The faintly visible band $\mathrm{C} 2$ is a complex of one DNA molecule with two protein molecules. (C) Structure specificity of binding. To the binding buffer containing $1.5 \mathrm{nM}$ of labeled cruciform DNA we added: $100 \mathrm{nM}$ (lane 1) or $10 \mathrm{nM}$ (lane 2) of unlabeled linear duplexes az and bz, respectively (lane 2 was loaded unevenly, with less material), and $10 \mathrm{nM}$ (lane 4 ) or $100 \mathrm{nM}$ (lane 5 ) of unlabeled four-way junction $z$. No unlabeled linear or cruciform DNA was added to lane 3 . Then we added purified recombinant HMG1 to each sample for a final concentration of $2 \mu \mathrm{g} / \mathrm{mL}$. In lane $\mathrm{C}$, we applied a control sample where no HMG1 was added. In either experiment, the samples were incubated for $5 \mathrm{~min}$ and assayed by electrophoresis. contained multiple insertions of the pPIC9-HMG1 BglII fragment.

To determine the number of copies of the HMG1 expression cassette, inserted $P$. pastoris $\mathrm{His}^{+} \mathrm{Mut}^{\mathrm{s}}$ chromosomal DNA was digested with $B g l \mathrm{II}$ and analyzed by Southern hybridization using a gel-purified HIS4 probe (Figure 1B). The number of copies inserted was determined on a PhosphorImager by the relative intensity of bands representing the single-copy, mutant chromosomal his4 gene $(2.7 \mathrm{~kb})$ and the HIS4 gene in the integrated expression cassette containing HMG1 $(6.4 \mathrm{~kb})$. In a single-copy insertion event, the two bands were of the same intensity (lane 9). Multiple insertions ranging from 2 (lane 8) to 6 (lane 2) copies were detected. Additional high-molecularweight bands were seen on two separate occasions with some of the clones (lanes 2, 4, 5, 7 and 8) and could be explained by the loss of $B g l$ II sites rather than incomplete restriction endonuclease digestion as reported previously (8).

\section{Protein Production and Western Blot Analysis}

The single-copy insertion clone A12 did not secrete protein detectable on PAGE gels by Coomassie blue staining or silver staining. Selected clones containing multiple integrations of the expression cassette were grown in the presence and absence of methanol, and the supernatants were analyzed by PAGE. The methanol medium contained two secreted protein species with molecular weights of approximately 24.5 and $32 \mathrm{kDa}$; no bands were seen in the absence of methanol (Figure 1C).

Western blot analysis showed that both protein species are recognized by the chicken anti-rat HMG1 antibody (Figure 2, lane 4b). The 32-kDa species contains large amounts of glycans, while the $24.5-\mathrm{kDa}$ species appears to be devoid of glycans (results not shown). Incubation of the proteins from the yeast supernatant with N-Glycosidase $\mathrm{F}$ resulted in the disappearance of the larger protein and in the increase of the protein co-migrating with mammalian HMG1 (results not shown). Thus, the larger protein species represents a glycosylated form of Pichiaproduced HMG1. 


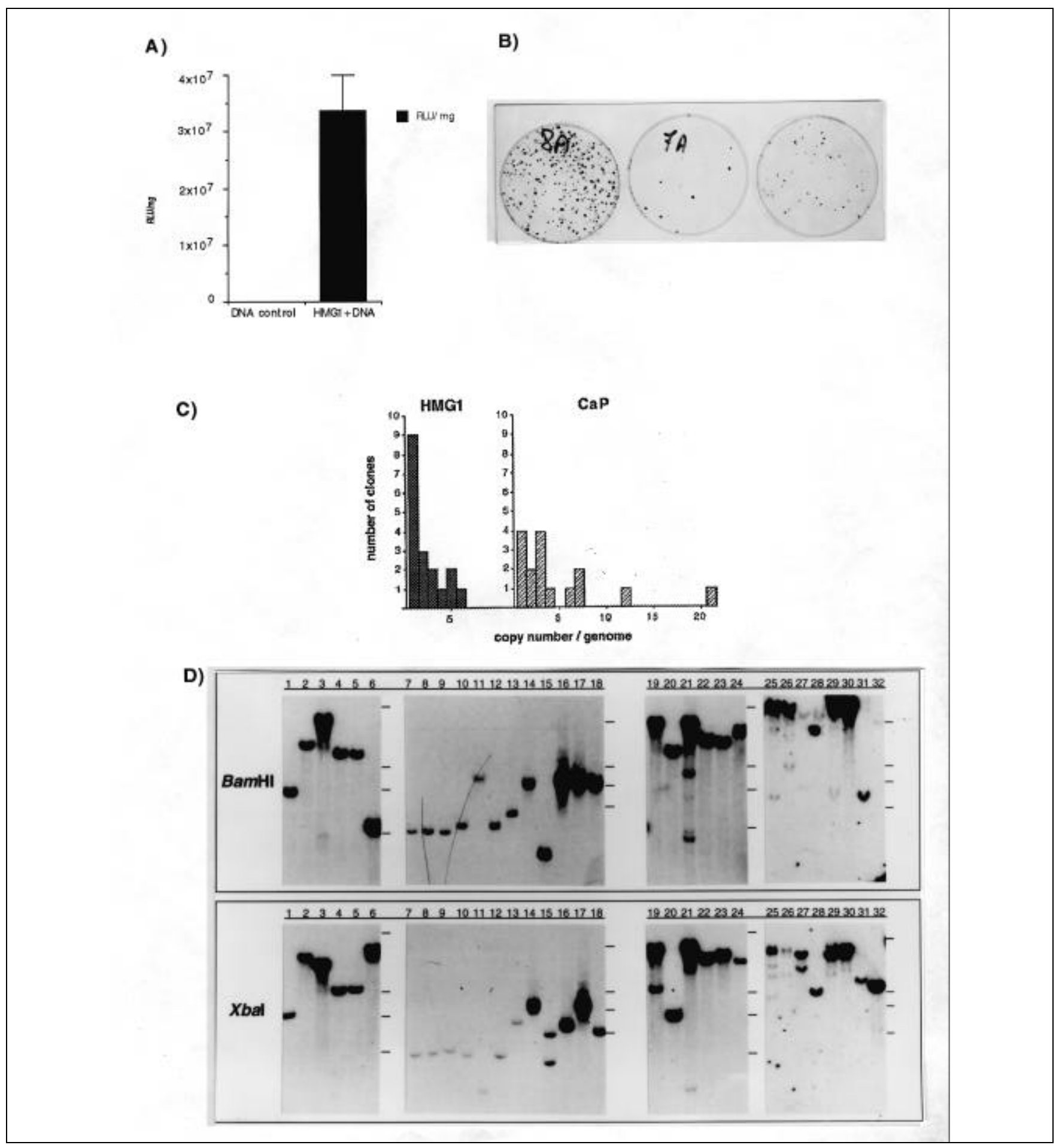

Figure 4. DNA transfecting activity of recombinant HMG1. (A) Transient expression of luciferase in transfected cells. $5 \mu \mathrm{g}$ of the luciferase reporter gene plasmid pGL2 were complexed with $300 \mu \mathrm{g}$ of the recombinant HMG1 in the presence of the OPTIMEM and then added to $50 \%$ confluent Caco-2 cells for $48 \mathrm{~h}$. Cellular protein was harvested and assayed for luciferase enzymatic activity using a luminometer-relative light units (RLU). The values obtained were then standardized per mg of total protein. Each column represents the mean of 3 observations, and error bars represent the standard deviation about the mean. DNA alone was used as a control for the transfection. (B) Representative petri dishes from one stable transfection of CHO dhfr- were photographed after colony-fixing and staining with crystal violet. Transfections were performed with $800 \mathrm{ng}$ of pSfiSVneo plasmid and lipofectin (left), calcium phosphate (middle) or nonglycosylated, purified HMG1 (right) as described in Materials and Methods. (C) Frequency distribution of integrated plasmid copy number. Dark columns: HMG1-transfected clones; light columns: calcium phosphate-transfected clones. (D) Southern blot analysis of genomic DNA from selected G418-resistant colonies. DNA samples were cleaved with either BamHI (upper) or XbaI (lower). Lanes 1-18, clones from HMG1-mediated transfection; lanes 19-32, clones from calcium phosphate-mediated transfection. Two of the calcium phosphate transfected clones were analyzed separately and are not shown here. Bars at the side of each panel indicate the position of the markers (12, 10, 8 and $6 \mathrm{~kb}$, respectively). 


\section{Research Reports}

\section{Purification of Pichia-Produced HMG1}

One of the clones, F11, was used to produce HMG1 that was purified to homogeneity by a three-step procedure (Figure 2). In the first step, the medium was acidified, and total secreted protein was recovered and concentrated by binding to a cationic high capacity column (Figure 2, lane 5). The two different-sized HMG1 species were eluted in the same fraction of a salt gradient. In the second step, the glycosylated form of recombinant HMG1 was removed by affinity chromatography on Con A, while the non-glycosylated form was recovered in the flow-through (Figure 2 , lane 6 ). The glycosylated form of the protein was eluted from the column at a low $\mathrm{pH}$ (Figure 2, lane 7). At this stage, recombinant HMG1 was still contaminated with traces of heterogeneous degradation products (Figure 2, lane 6). In the third step, full-length recombinant HMG1 was purified to homogeneity on the anionic column (HiTrap Q), but only the complete protein, by means of its acidic tail, can bind to this support (Figure 2, lane 8). This principle was also adopted in the final step of HMG1 purification from calf thymus. Recombinant HMG1 and thymus-purified HMG1 showed the same elution profile, dissociating from the resin at approximately $0.5 \mathrm{M} \mathrm{NaCl}$ (data not shown). The total yield of recombinant, purified, non-glycosylated HMG1 was about $50 \mathrm{mg} / \mathrm{L}$ of BMMY medium.

\section{DNA Binding}

The ability of secreted recombinant, non-purified HMG1 to bind plasmid DNA was monitored by a gel-retardation assay (Figure 3A). The electrophoretic migration pattern was characteristic of HMG1-plasmid DNA complexes because it retarded the mobility of negatively supercoiled DNA more than the nicked circular form (24). At a ratio of approximately 7000:1 (mol:mol) of HMG1 to DNA, all the supercoiled DNA seemed to have been retarded, and therefore complexes made in this ratio were used to transfect tissue-cultured cells.

The binding of cruciform DNA is characteristic of native HMG1 $(3,5)$.
The purified Pichia-produced HMG1 bound specifically to four-way junctions created by the annealing of ${ }^{32} \mathrm{P}-$ labeled oligonucleotides and not to linear DNA structures formed by the same oligonucleotides. This can be seen by the presence of the HMG1-junction DNA complex bands $\mathrm{C} 1$ and $\mathrm{C} 2 \mathrm{mi}-$ grating slower than free-junction DNA band $\mathrm{F}$ (Figure $3 \mathrm{~B}$ ). This binding was completed by unlabeled cruciform DNA but not by linear DNA (Figure 3C). The cruciform-binding activity of Pichia-produced HMG1 was identical to that of HMG1 purified from thymus (Figure 3B). The purified glycosylated form of the protein also bound cruciform DNA in a similar manner (results not shown ).

\section{Transient and Stable Transfection of Mammalian Cells}

HMG1 and pGL2 plasmid DNA were mixed in a ratio of 7000:1 (mol: mol) and 60:1 (wt:wt) and used to transfect Caco-2 cells (Figure 4A). Remarkably, even cells treated with very high levels of HMG1 alone or HMG1/ DNA complexes (up to $2 \mathrm{mg} / \mathrm{mL}$ ) do not show any trace of damage, as determined by trypan blue exclusion or lactate dehydrogenase release (results not shown).

$\mathrm{CHO} \mathrm{dhfr}^{-}$cells were transfected with complexes between HMG1 and plasmid pSfiSVneo, carrying the neomycin resistance gene $\left(\mathrm{neo}^{\mathrm{R}}\right)$ under the control of the SV40 early promoter. G418-resistant colonies were generated from cells treated with HMG1/DNA complexes, whereas parallel transfections with DNA alone yielded no colonies. The number of colonies obtained varied in different experiments, but was generally comparable to control transfections performed by calcium phosphate co-precipitation. Lipofection was about ten times more efficient (Figure 4B).

Genomic DNA extracted from selected G418-resistant clones from both HMG1- and calcium phosphate-mediated transfections was analyzed by Southern blot. To determine the number of integrated expression units (both concatenized and discrete plasmids), genomic DNA was cleaved with HindIII plus $N c o$ I, which excise a 916-bp 
fragment from the neo ${ }^{\mathrm{R}}$ cDNA region, and probed with the same fragment. Densitometric analysis of the resulting 916-bp bands (results not shown) allowed us to calculate the copy number of the integrated plasmid (Figure 4C). While most of the HMG1-transfected clones (9/18) displayed one integrated copy per genome and contained, at most, 6 copies, the frequency distribution was more widely spread for calcium phosphate-transfected clones, with only 4/16 clones containing one copy and one clone reaching 21 copies.

Genomic DNA extracted from the clones was also digested separately with BamHI and $\mathrm{XbaI}$ (sites that are not present on the pSfiSVneo plasmid). This enabled us to determine the number of integration events (Figure 4D). Seventeen out of 18 HMG1-transfected clones showed a single integration site, while one had two sites (verified by the presence of two bands in lane 15 on the
$X b a I$ blot); 6/14 calcium phosphatetransfected clones, on the other hand, showed more than one integration site.

Similar results were obtained with 3 T3 mouse fibroblasts, HeLa cells and human 129 cells (not shown), suggesting that a wide range of mammalian cell lines may be amenable to HMG1mediated transfection.

\section{DISCUSSION}

We report here the high-level production and purification of HMG1 from the yeast $P$. pastoris and demonstrate the ability of recombinant HMG1 to mediate gene transfer and expression in tissue-cultured cells.

The production of HMG1 was dependant upon the multiple insertion of the linearized expression cassette pPIC9-HMG1 into the yeast genome since HMG1 was only expressed from multicopy recombinants and not from single-copy transformants, such as A12. The whole process from subcloning the HMG1 cDNA into the pPIC9 vector to production could be achieved within a six-week period. The mechanism by which multiple copies of the expression cassette are integrated in the genome in the correct orientation is thought to occur by recirculation of the $B g l$ II fragment of the pPIC9-HMG1 cassette in vivo followed by repeated single crossover events at the site of the initial gene replacement (8).

Recombinant HMG1 from Pichia consisted of a native-sized form of HMG1 (24.5 kDa) and a glycosylated derivative $(32 \mathrm{kDa})$. The $P$. pastoris glycosylation mechanism resembles that of higher eukaryotes since it proceeds by the $\mathrm{N}$-linked addition of oligosaccharides of the high-mannose type (10). HMG1 has two potential sites for N-linked glycosylation: amino 
acid positions 46-48, NFS and 143145 , NNT. Treatment with N-Glycosidase $F$ caused a shift in the size of the $32-\mathrm{kDa}$ species to that of the native form, indicating that HMG1 was glycosylated with the high mannose-type oligosaccharide. The presence of both glycosylated and non-glycosylated HMG1 species, in approximately a 2:3 ratio, suggests that the glycosylation process at one or both of these sites in the endoplasmic reticulum is inefficient or that the glycosylation mechanism is overwhelmed by the amount of HMG1. The glycosylated form was removed by affinity-binding to a column-bound lectin, enabling the separation of the non-glycosylated form to homogeneity.

DNA binding assays showed that both the purified non-glycosylated and glycosylated recombinant HMG1 selectively bound to the synthetic cruciform DNA but not to linear DNA duplex molecules of identical sequence.
They were also shown to interact more effectively with negatively supercoiled DNA than with nicked circular DNA. These observations are characteristic of HMG1 $(5,24)$ and indicate that the recombinant HMG1 is fully active and properly folded.

We have demonstrated that complexes consisting of Pichia-produced recombinant HMG1 and exogenous DNA can be used to transfect a variety of cultured mammalian cells. Both transient expression and expression as a result of stable integration into the cell genome were observed. The purified glycosylated form of the protein was not used for transfection; we have found that the purified glycosylated protein forms aggregates when trying to complex with DNA. These aggregates may form as a result of interactions between the sugar moieties. HMG1-mediated gene delivery has several advantages over other methods of transfection. In contrast to calcium phosphate and electroporation, cells subjected to HMG1-mediated transfection are not damaged in any way, and there is no need to alter conditions between different cell lines. In addition, we have shown that HMG1-mediated transfections promote one or few copies of the exogenous DNA to integrate into the genome compared to the calcium phosphate method in which large, unpredictable numbers are usually integrated. This property makes HMG1 useful for transfecting plasmid constructs that have been used to study gene regulation where integration of a single copy is important. The mechanism by which HMG1 translocates through the plasma membrane is not known, although it probably interacts with negatively charged polysaccharides on the cell surface (L. Falciola, unpublished results). In conjunction with its extremely low immunogenici- 
ty, these features make HMG1 an attractive agent for gene delivery in vivo.

We now have a convenient source of HMG1 and a system to design and produce genetically modified derivatives of HMG1 to further study and possibly to enhance its transfection ability. HMG1 secretion is, to our knowledge, the first reported production of a functional recombinant DNA-binding protein by $P$. pastoris, which indicates that this system is likely to be amenable to other DNA-binding proteins including transcription factors. The production of HMG1 from $P$. pastoris provides an abundant, inexpensive source of this biologically important protein which will be valuable not only as a transfecting agent, but also in determining its structural features and physiological role.

\section{ACKNOWLEDGMENTS}

We are grateful to Volker Sandig, Michael Böttger, Bob Williamson and Luisa Guerrini for advice on transfections and discussion. We thank the Association Française de Lutte Contre la Mucoviscidose, Association Française Contre les Myopathies, the Leopold Muller Bequest and the Medical Research Council for their financial support to the St. Mary's based group; Telethon for support to M.E.B. and L.M.

\section{REFERENCES}

1.Anand, R. and E.M. Southern. 1989. Gel electrophoresis of nucleic acid: a practical approach. IRL Press, Oxford.

2.Barr, K.A., S.A. Hopkins and K. Sreekrishna. 1992. Protocol for efficient secretion of HSA developed from Pichia pastoris. Pharm. Eng. 12:48-51.

3.Bianchi, M.E. 1988. Interaction of a protein from rat liver nuclei with cruciform DNA. EMBO J. 7:843-849.

4.Bianchi, M.E. 1991. Production of functional rat HMG1 protein in Escherichia coli. Gene 104:271-275.

5.Bianchi, M.E., M. Beltrane and G. Paonessa. 1989. Specific recognition of cruciform DNA by nuclear protein HMG1. Science 243:1056-1059.

6.Böttger, M., F. Vogel, M. Platzer, U. Kiessling, K. Grade and M. Strauss. 1988. Condensation of vector DNA by the chromosomal protein HMG1 results in efficient transfection. Biochim. Biophys. Acta 950:221-228.

7.Bustin, M., D.A. Lehn and D. Landsman.
1990. Structural features of the HMG chromosomal proteins and their genes. Biochim. Biophys. Acta 1049:231-243.

8.Clare, J.J., F.B. Rayment, S.P. Ballantine, K. Sreekrishna and M.A. Romanos. 1991. High-level expression of tetanus toxin fragment $\mathrm{C}$ in Pichia pastoris strains containing tandem integrations of the gene. Bio/Technology 9:455-460.

9.Clare, J.J., M.A. Romanos, F.B. Rayment, J.E. Rowedder, M.A. Smith, M.M. Payne, K. Sreekrishna and C.A. Henwood. 1991 Production of mouse epidermal growth factor in yeast: high-level secretion using Pichia pastoris. Gene 105:205-212.

10.Cregg, J.M., T.S. Vedvick and W.C. Raschke. 1993. Recent advances in the expression of foreign genes in Pichia pastoris. Bio/Technology 11:905-910.

11.Falciola, L., A.I. Murchie, D.M. Lilley and M. Bianchi. 1994. Mutational analysis of the DNA binding domain A of chromosomal protein HMG1. Nucleic Acids Res. 22:285-292.

12.Feinberg, A. and B. Volgelstein. 1983. A technique for radiolabelling DNA restriction endonuclease fragments to high specific activity. Anal. Biochem. 132:6-13.

13.Ferrari, S., V.R. Harley, A. Pontiggia, P.N. Goodfellow, R. Lovell-Badge and M.E. Bianchi. 1992. SRY, like HMG1, recognises sharp angles in DNA. EMBO J. 11:4497-4506.

14.Graham, F.L. and A.J. van der Eb. 1973. A new technique for the assay of infectivity of human adenovirus 5 DNA. Virology 52:456467.

15.Grosschedl, R., K. Giese and P. Pagel. 1994. HMG domain proteins: architectural elements in the assembly of nucleoprotein structures. Trends Genet. 10:94-100.

16.Isackson, P.J., J.L. Fishback, D.L. Bidney and G.R. Reeck. 1979. Preferential affinity of high mobility group non-histone chromatin proteins for single-stranded DNA. J. Biol. Chem. 254:5569-5572.

17.Kaneda, Y., K. Iwai and T. Uchida. 1989. Increased expression of DNA cointroduced with nuclear protein in adult rat liver. Science 243:375-378.

18.Kohlstaedt, L.A. and R.D. Cole. 1994. Specific interaction between $\mathrm{H} 1 \mathrm{Histone}$ and High Mobility protein HMG1. Biochemistry 33:570-575.

19.Marekov, L.N., D.G. Demirov and B.G. Beltchev. 1984. Isolation of High-MobilityGroup proteins HMG1 and HMG2 in non denaturing conditions and comparison of their properties with those of acid-extracted proteins. Biochim. Biophys. Acta 789:63-68.

20.Meinkoth, J. and G. Wahl. 1984. Hybridisation of nucleic acids immobilised on solid supports. Anal. Biochem. 138:267-268.

21.Miller, S.A., D.D. Dykes and H.F. Polesky. 1988. A simple salting out procedure for extracting DNA from human nucleated cells. Nucleic Acids Res. 16:1215.

22.Monaco, L., R. Taglibue, M.R. Soria and M. Uhlen. 1994. An in vitro amplification approach for the expression of recombinant proteins in mammalian cells. Biotechnol. Appl. Biochem. 20:157-171.

23.Romanos, M.A., J.J. Clare, K.M. Beesley, F.B. Rayment, S.P. Ballantine, A.J. Makoff,
G. Dougan, N.F. Fairweather and I.G. Charles. 1991. Recombinant Bordettella pertussis pertactin (P69) from the yeast Pichia pastoris: high-level production and immunological properties. Vaccine 9:901-906.

24.Sheflin, L.G., N.W. Fucile and S.W. Spaulding. 1993. The specific interactions of HMG1 and 2 with negatively supercoiled DNA are modulated by their acidic C-terminal domains and involve cysteine residues in their HMG $1 / 2$ boxes. Biochemistry 32:3238-3248.

25.Sheflin, L.G., and S.W. Spaulding. 1989. High Mobility Group Protein 1 preferentially conserves torsion in negatively supercoiled DNA. Biochemistry 28:5658-5664.

26.Tschopp, J.F., G. Sverlow, R. Kosson, W. Craig and L. Grinna. 1987. High level secretion of glycosylated invertase in the methylotrophic yeast Pichia pastoris. Bio/Technology 5:1305-1308.

27.Vedvick, T., R.G. Buckholz, M. Engel, M. Urcan, J. Kinney, S. Provow, R.S. Siegel and G.P. Thill. 1991. High-level secretion of biologically active aprotinin from the yeast. J. Ind. Microbiol. 7:197-201.

28.Wagner, J.P., M. Quill and D.E. Pettijohn. 1995. Increased DNA-bending activity and higher affinity DNA binding of High Mobility Group Protein HMG1. J. Biol. Chem. 270:7394-7398.

Received 1 July 1996; accepted 25 November 1996.

Address correspondence to:

Ajay R. Mistry

Department of Biochemistry and Molecular Genetics

Imperial College School of Medicine at St. Mary's Norfolk Place, London, W2 1PG, England, UK

Internet:arm30@ic.ac.uk 